\title{
SHORT TERM EFFECT OF HEMODIALYSIS ON PERIPAPILLARY RETINAL NERVE FIBER LAYER AND MACULAR THICKNESS
}

\author{
Bushra Jabbar, Qamar Ul Islam*, Muhammad Kashif Hanif, Ubaidullah Yasin, Omer Farooq, Saman Fatima** \\ Pakistan Naval Ship, Shifa Hospital, Karachi/National University of Medical Sciences (NUMS) Pakistan, *Combined Military Hospital, \\ Malir/National University of Medical Sciences (NUMS) Pakistan, **Pakistan Naval Ship, Rahat, Karachi/National University of Medical \\ Sciences (NUMS) Pakistan
}

\begin{abstract}
Objective: To determine the thicknesses of retinal nerve fiber layer (RNFL) and macula by fourier-domain (FD) optical coherence tomography (OCT) in diabetic patients with end-stage renal failure (ESRF) undergoing hemodialysis.

Study Design: Cross-sectional study.

Place and Duration of Study: Pakistan Naval Ship, Shifa Karachi, from Jan 2019 to Jul 2019

Methodology: Fifty four patients presenting to nephrology department who met the inclusion criteria were included in the study. Macular and retinal nerve fibre layer thicknesses were compared pre and post 30 minutes of hemodialysis and their correlation $(\mathrm{r}=-0.89)$ with age, duration of hemodialysis and gender was examined. Pre hemodialysis temporal, inferior, average retinal nerve fibre layer thicknesses were observed thinner than Post hemodialysis.

Results: Pre-hemodialysis macular thicknesses were thinner than post hemodialysis. Thinning of Macular and RNFL showed a negative relationship with age and duration of hemodialysis ( $\mathrm{r}=-0.89 \&-0.76$ ). Temporal, superior quadrants and average retinal nerve fiber layer thickness values were found statistically different in pre and post 30 minutes hemodialysis examination $(p$-value $=0.002,0.001 \& 0.0021)$ while, nasal and inferior quadrants were found statistically insignificant. Whereas in macula, temporal and superior quadrants were found statistically significant $(p$-value $=0.005 \& 0.002)$ and nasal, Inferior and average thickness were found statistically insignificant ( $p$-value $=0.0641,0.0594 \& 0.083)$.

Conclusion: Macular and retinal nerve fiber layer thicknesses of patients receiving hemodialysis were less than the normal population. Age has no effect on these thinning. The duration of hemodialysis effects more than gender. Hemodialysis session causes a consistent increase in superior quadrant retinal nerve fiber layer. Retinal nerve fiber layer and macula showed a negative relationship with age and duration of hemodialysis.
\end{abstract}

Keywords: Endstage renal failure, Hemodialysis, Macular thickness, Retinal nerve fibre layer thickness.

This is an Open Access article distributed under the terms of the Creative Commons Attribution License (http://creativecommons.org/licenses/by/4.0), which permits unrestricted use, distribution, and reproduction in any medium, provided the original work is properly cited.

\section{INTRODUCTION}

Patients with glomerular filtration rate $>15$ $\mathrm{ml} / \mathrm{min}$ have end stage renal failure. Diabetes mellitus is one of the significant factors of renal failure in United States (US). The renal failure mostly tracks hypertensive nephropathy. Patients with ESRF undergo hemodialysis ${ }^{1}$. Patients with chronic renal failure have anemia and other risk factors like hypertension, anterior ischemic and uremic optic neuropathy ${ }^{2}$.

The optic disc and the physical structure of

Correspondence: Dr Bushra Jabbar, Flat No. 602, Rainbow Center, Saddar Karachi Pakistan

Received: 27 Mar 2020; revised received: 12 May 2020; accepted: 29 May 2020 the human retina can be studied with optical coherence tomography (OCT), which is highly resolutional approach. This approach was used to see the retinal nerve fiber layer of the patients with chronic renal failure ${ }^{3}$. Every third patient of the hemodialysis without any aortic obstruction had rapid decline in the retinal light sensitivity. This decrease in retinal sensitivity showed no correlation with age and duration of hemodialysis, whereas in patients with significant hypertensive retinopathy, OCT showed reduced thickness of retina in hemodialysis patients, but it didn't show any significant correlation with duration of hemodialysis and found a significant relationship with age of patients 4 . The rationale of 
the study wasto find the effects of hemodialysis on retinal nerve fibre layer and macular thickness so that if hemodialysis affects retina adversely timely interventions can be taken including more frequent followup as these patients are already at greater risk of complications due to comorbidities.

\section{METHODOLOGY}

It was a cross-sectional study conducted in PNS Shifa, Karachi from January, 2019 to July, 2019. A total of 54 patients were selected consecutively through universal sampling method from the Nephrology department, Pakistan Naval Ship Shifa. Various demographic and medical characteristics of the patients were compared pre and post 30 minutes of hemodialysis using various statistical tools. Consent form was signed by the participants which was being approved by the Ethics review committee. Exclusion criteria included patients with history of glaucoma and intraocular surgery, corneal opacities, cataract, age below $^{15}$ and $>65$ years, refractive error more than $(-1,+1)$ diopters and uncontrolled hypertension.

The dialysis was performed using various quantities of Potassium, Calcium and heparin as an anti-coagulant. During hemodialysis, velocity of blood flow supposed to be $350 \mathrm{ml} / \mathrm{min}$ with 4 hours duration.

Many other parameters related to hemodialysis such as blood urea, creatinine, total protein, albumin, sodium, potassium, calcium, phosphate, hematocrit and hemogram, blood glucose, systolic and diastolic blood pressure were documented pre and post hemodialysis session. Amount of fluid removed from the body at the time of dialysis was also documented. To analyze the data, various statistical techniques were used to compare medical and demographic characteristics of the patients. All the statistical analysis was performed in statistical package for social sciences (SPSS) version 23. Both descriptive and inferential statistics was performed. Demographic variables being described by descriptive statistics, while associated risk factors determined by t-test and correlation analysis. The $p$-value $\leq 0.05$ was considered significant.

\section{RESULTS}

For 54 patients including 45 (83\%) male and $9(17 \%)$ female patients, the average interval of hemodialysis per patient was $3.4 \pm 3.08$ years. Mean age of the patients was $37.7 \pm 12.2$ years having blood glucose level of the patients as $300 \pm$ $22.4 \mathrm{mg} / \mathrm{dl}$ (table-I).

Table-I: Demographic and clinical characteristics of patients.

\begin{tabular}{l|c}
\hline Characteristic & Hemodialysis \\
\hline Total patients & 54 \\
\hline Age, mean \pm SD (range) & $37.7 \pm 12.2(46)$ \\
\hline Male/Female & $45(83 \%) / 9(17 \%)$ \\
\hline Random blood sugar & $300 \pm 22.4 \mathrm{mg} / \mathrm{dl}$ \\
\hline The duration of hemodialysis & $3.4 \pm 3.08$ \\
(years), Mean \pm SD (range) & $(11.82)$ \\
\hline Hypertension & $14(25.92 \%) /$ \\
\hline Best corrected visual acuity, & $20(37.03 \%)$ \\
mean (range) & $0.96 \pm 0.02$ \\
\hline
\end{tabular}

Table-II defines various parameters of retinal nerve fiber layer thickness pre and post 30 minutes of hemodialysis. Parameters regarding retinal nerve fiber layer (RNFL) and Maculawere found statistically significant at 5\% level of significance indicating a significant difference in the various parameter of RNFL and Macula pre and post 30 minutes of the hemodialysis. Pre and post hemodialysis session macular thicknesses were found statistically significant $(p<0.01)$ (table-II).

Thickness of the RNFL and macula as measured by OCT pre and post 30 minutes hemodialysis aredescribed in table-III. Temporal quadrant RNFL thickness value were found statistically different in pre and post 30 minutes hemodialysis examination as the $p$-value is less than $5 \%$ ( $p$-value $=0.002)$. Also, Superior and average RNFL thickness values in pre and post 30 minutes hemodialysis examination were found significantly different as $p$-value is $<5 \%$ i.e. 0.001 and $0.0021(<0.05)$. Whereas the thickness of nasal and inferior quadrants RNFL differs statistically in- 
significant pre and post 30 minutes hemodialysis examination.

Thickness of macula in temporal and superior quadrants were found statistically significant as $p$-values for these quadrants are 0.005 and which was found to be negative and statistically significant at $5 \%$ level of significance. The tableIV shows correlation coefficient of the Macula with age and duration of hemodialysis. The table shows a significant negative relationship with age

Table-II: Pre and post hemodialysis (HD) thicknesses of RNFL and macula.

\begin{tabular}{|c|c|c|c|}
\hline Quadrants & Hemodialysis (Pre) & 30 minutes (Post) & $p$-value \\
\hline \multicolumn{4}{|c|}{ Retinal Nerve Fiber Layer Thickness } \\
\hline Temporal & $66.54 \pm 11.19$ & $90.10 \pm 15.53$ & $<0.01$ \\
\hline Superior & $122.14 \pm 20.18$ & $132.9 \pm 17.77$ & $<0.01$ \\
\hline Nasal & $72.59 \pm 17.09$ & $79.48 \pm 15.26$ & $<0.01$ \\
\hline Inferior & $118.42 \pm 15.00$ & $132.63 \pm 16.34$ & $<0.01$ \\
\hline Average & $94.92 \pm 15.87$ & $108.77 \pm 16.23$ & 0.001 \\
\hline \multicolumn{4}{|l|}{ Macular } \\
\hline Temporal & $265.34 \pm 23.15$ & $296.36 \pm 21.65$ & $<0.01$ \\
\hline Superior & $276.24 \pm 19.45$ & $302.45 \pm 18.22$ & $<0.01$ \\
\hline Nasal & $292.17 \pm 20.36$ & $300.11 \pm 16.17$ & $<0.01$ \\
\hline Inferior & $286.32 \pm 21.05$ & $298.44 \pm 18.22$ & $<0.01$ \\
\hline Average & $280.07 \pm 20.78$ & $299.34 \pm 18.56$ & 0.005 \\
\hline \multicolumn{4}{|c|}{ Table-III: Pre and post 30 minutes hemodialysis (HD) retinal nerve fiber layer (RNFL) and macular thickness. } \\
\hline Quadrants & Pre hemodialysis & Post 30 minutes HD & $p$-value \\
\hline \multicolumn{4}{|c|}{ Retinal Nerve FiberLayer } \\
\hline Temporal & $78.8 \pm 9.14$ & $80.2 \pm 13.7$ & 0.002 \\
\hline Superior & $126.8 \pm 24.8$ & $131.56 \pm 25.1$ & 0.001 \\
\hline Nasal & $78.1 \pm 14.6$ & $78.3 \pm 14.9$ & 0.065 \\
\hline Inferior & $121.9 \pm 19.0$ & $126.25 \pm 20.2$ & 0.0725 \\
\hline Average & $101.4 \pm 16.8$ & $104.07 \pm 18.51$ & 0.0021 \\
\hline \multicolumn{4}{|l|}{ Macula } \\
\hline Temporal & $280.2 \pm 21.51$ & $283.35 \pm 24.3$ & 0.005 \\
\hline Superior & $280.4 \pm 23.5$ & $281.48 \pm 24.2$ & 0.002 \\
\hline Nasal & $279.2 \pm 22.9$ & $282.85 \pm 23.1$ & 0.0641 \\
\hline Inferior & $280.1 \pm 22.0$ & $284.31 \pm 22.9$ & 0.0594 \\
\hline Average & $272.99 \pm 22.47$ & $294.87 \pm 23.63$ & 0.083 \\
\hline
\end{tabular}

0.002 respectively, whereas for nasal, inferior quadrants and average thickness were found statistically insignificant as the $p$-values are 0.0641 , 0.0594 and 0.083 respectively in pre and post 30 minutes hemodialysis examination. (The $p$-value is greater than $5 \%$.)

To find correlation between various characteristics of patients and thickness of the retinal nerve fiber layer, Pearson correlation coefficient was computed, and their significance was studied. The following table indicates the correlation coefficient of RNFL and Macula with various factors.

The table-IV shows correlation coefficient of the RNFL with age and duration of hemodialysis and insignificant relationship with the duration of hemodialysis at $5 \%$ level of significance.

Table-IV: Pearson correlation coefficient along significance value ( $p$-value).

\begin{tabular}{l|c|c}
\hline Factors & RNFL & Macula \\
\hline Age & $-0.89(0.000)$ & $-0.76(0.000)$ \\
\hline $\begin{array}{l}\text { Duration of } \\
\text { Hemodialysis }\end{array}$ & $-0.64(0.000)$ & $0.004(0.249)$ \\
\hline
\end{tabular}

\section{DISCUSSION}

Endstage renal failure patients treated with hemodialysis have higher incidence of ophthalmic complications including diabetic retinopathy, diabetic macular edema and hypertensive retinopathy. OCT is gold standard for evaluating peripapillary nerve fiber layer of retina and macular 
thickness. Macular thickness of 12 hemodialysis patients were analyzed and compared with the healthy individuals using OCT5 ${ }^{5}$. Age of the hemodialysis patients with RNFL thickness showed a positive correlation ${ }^{6}$. Igiranza et al conducted study of patients with acute renal failure requiring hemodialysis in Rwanda. This retrospective study assessed the clinical outline and survival outcomes of patients at a tertiary hospital in Rwanda. Data collected from September, 2014 to September, 2016. Demographic, comorbidities, presenting features, laboratory tests and mortality were studied and analyzed. Multivariate analysis was used to find the predicators of mortality. Results showed that the acute hemodialysis improved patients survival and persistent hyperkalemia predicted higher mortality.

Sa'ed et al ${ }^{8}$ studied factors which effect the patients undergoing hemodialysis in Palestine. A cross sectional study was conducted from June, 2014 to January, 2015. Patients with End-stage renal failure undergoing hemodialysis were included in study. Multiple regression was performed to recognize significant factors linked with HRQOL. Two hundred and sixty seven patients were included in the study who responded at rate of $96 \%$. Multiple regression results showed negative substantial association of HRQOL with age, number of chronic comorbidities andchronic patients, but it showed positive substantial association of HRQOL with male gender and university education.

Mushi et al ${ }^{9}$ systematically reviewed the peer reviewed articles on cost of hemodialysis in countries with lowand middleclass income and indicated that dialysis is an expensive treatment and poorest countries had an over proportional burden to finance dialysis.

A descriptive cross-sectional study was performed in the hemodialysis unit from February 12, 2015 to May 15, 2015. Patients undergoing dialysis for atleast three months were included in the study. Sociodemographic and clinical data was collected from 172 patients. Main suspicious cases of CRF were chronic glomerulonephritis and hypertension. Second source appeared to be often infectious. CRF prevention in Burkina Faso focused on hypertension and infectious disease ${ }^{10}$. Chironda et al ${ }^{11}$ conducted a correlation study to discuss the health conditions of ESRD patients and the willingness of hemodialysis in Zimbabwe. Simple random sample of 85 patients of ESRD were selected from the central hospital in Harare. Data was collected by schedule interview method on demographic, health status and adherence level of hemodialysis. Pearson's correlation coefficient and the regression model was used to study the impact of the health condition of patients on adherence level for hemodialysis and concluded a negative correlation with the value of R2 as $19.7 \%$ in the adherence level of hemodialysis. Ninety six percent of patients in sample had average health conditions. The study forecasted that increasing health condition will lead to decrease in adherence level to hemodialysis in ESRD patients.

Yuen et al12 conducted a followup study regarding advancement in health care planning for the patients of end stage renal disease (ESRD) in China. This study was conducted from June, 2006 to December, 2011 in which patients were given choice to make decision about the future health care plan. In this study, 600 patients were followed up for about 782 average (median) number of days. The study concluded that about $1.6 \%$ of patients changed decision to hemodialysis. Modified charlson comorbidity index score computed for patients and decline observed in the survival score. Deif et al13 investigated the effects of educational program on adherence to therapeutic regimen among CKD5 (stage 5) patients under maintenance hemodialysis. To achieve the purpose of the study, purposive sample of sixty adults that underwent hemodialysis for atleast six months, and not more than a year were allocated. Repeated and frequent contact with renal nurses helped these patients to develop problem solving skills, set goals and understand their progress in managing different aspects of disease. Personalizing a collaborative educational approach supports self-control by 
incorporating the patient's belief, behaviors and physical and mental well-being, as well as culture, economic situation and knowledge of the disease and its treatment.

Mukakarangwa et al ${ }^{14}$ studied a cross-sectional study to determine the extent of adherence and allied factors with hemodialysis in patients of endstage renal disease for Rwanda. In this descriptive study, 41 patients were selected by nonprobability sampling i.e. purposive sampling. Data regarding the level of adherence to hemodialysis was obtained using a structural interview method. The demographic characteristics of the patients were described by descriptive statistics while chi-square test and the confidence interval were used as inferential statistical methods. Chisquare test was used to determine the related factors. Confidence interval approach determined the interval estimates for the important factors. Age, religion, qualification of workers at healthcare center and facing difficulties during hemodialysis were observed as significant factors related to adherence level of patients. Matsuo ${ }^{15}$ discussed the retinal thickness by considering the two groups of patients of hemodialysis and determined the impact of age, gender and hemodialysis duration. This study showed the acute impact of hemodialysis on retina in patients of end-stage-renal-failure. Pre and post hemodialysis thickness of the intima media was compared in patients. The study showed a significant difference in pre and post hemodialysis retinal thickness.

A correlational study was conducted to study the relationship of retinal nerve fiber layer thinning with various factors for 251 patients of hemodialysis. The study showed a significant positive relationship of retinal nerve fiber layer with age, gender and axial length ${ }^{16}$. Retinal Nerve Fiber Layer became thinner as the age and axial length increase while optic disc diameter decreases. The gender of the patient has significant effect on retinal nerve fiber layer. The study showed optic discs are thinner in females ${ }^{17}$. In a study, the common carotid artery's intima-media was found considerably thicker in patients under- going HD as compared to controls. This thickening had a positive correlation with age but a negative correlation with period of HD. These studies found carotid artery obstruction to be responsible for retinal ischemia which led to reduced thickness of the retina ${ }^{18}$.

The description of demographic and clinical parameters for 54 patients,consisting of 45 male and 9 females showed an average interval of hemodialysis per patient to be 3.4 years. Of $95 \%$ confidence interval of the age of the patients was $37.7 \pm 12.2$ years having blood glucose levels 300 $\pm 22.4 \mathrm{mg} / \mathrm{dl}$. Significance of various parameters of retinal nerve fiber layer and macular thickness pre and post 30 minutes of hemodialysis was determined. A significant differencewas found in various parameters of RNFL and Macula pre and post 30minutes of hemodialysis. Thickness of the macula before and after hemodialysis were found statistically significant $(p<0.00)$. Average of all the parameters of RNFL and Maculawere found statistically significant at 5\% level of significance. Superior and average RNFL thickness values pre and post-hemodialysis were found significantly thicker i.e. $(p<0.05)$. Thickness of all the quadrants of macula except for average thickness were insignificantly thicker post-hemodialysis session. There found a negative relationship between these mentioned factors, while no significant relationship with age of the patient.

\section{CONCLUSION}

This study steered to compare and determine the relationship of thickness of RNFL and macula indiabetic patientswith demographic and related characteristics undergoing hemodialysis. Thicknesses of Macula and RNFL were compared pre and post 30 minutes of hemodialysis and correlation with age,blood glucose level, duration of hemodialysis examined. This thinning was not associated with age and duration of hemodialysis. Prehemodialysis macular thicknesses were thinner than post-hemodialysis. These thinning showed no relationship with age, however thinning at superior, nasal quadrants along with average thicknesses were found to be negatively 
associated with duration of hemodialysis. Female patients showed reduced nasal, temporal and average macular thickness. RNFL and macular thicknesses observed on the first day and $30 \mathrm{mi}-$ nutes post-hemodialysis session showed no consistency except RNFL thickness in superior quadrant. Macular and RNFL thickness were less than the normal population. Age has no effects on these thinning. Duration of hemodialysis affects more than gender.

\section{CONFLICT OF INTEREST}

This study has no conflict of interest to be declared by any author.

\section{REFERENCES}

1. Brenner BM, Secondary glomerular disease. Brenner \& Rector's. Kidney. 8th ed. 2008: 1097-1099. Available from: https:// doctorlib.info/nephrology/kidney/32.html

2. Mullaem G, Rosner MH. Ocular problems in the patient with end stage renal disease. In Seminars in dialysis Oxford, UK: Blackwell Publishing Ltd. Semin Dial 2012; 25(4): 403-07.

3. Demir MN, Ekşioğlu Ü, Altay M, Tök Ö, Yilmaz FG, Acar M, et al. Retinal nerve fiber layer thickness in chronic renal failure without diabetes mellitus. Eur J Ophthalmol 2009; 19(6): 1034-38.

4. Pahor D. Reduction of retinal light sensitivity in diabetic patients. Klin Monbl Augenheilkd 2003; 220(12): 868-72.

5. Pahor D, Gracner B, Gracner T, Hojs R. Optical coherence tomography findings in hemodialysis patients. Klin Monbl Augenheilkd 2008; 225(8): 713-17.

6. Balazsi AG, Rootman J, Drance SM, Schulzer M, Douglas GR. The effect of age on the nerve fiber population of the human optic nerve. Am J Ophthalmol 1984; 97(6): 760-66.

7. Igiraneza G, Ndayishimiye B, Nkeshimana M, Dusabejambo V. Clinical profile and outcome of patients with acute kidney injury requiring hemodialysis: Two years' experience at a tertiary hospital in Rwanda. Bio Med Res Intl 2018; 1716420: 1-6.

8. Sa'ed HZ, Daraghmeh DN, Mezyed DO, Khdeir RL, Sawafta $\mathrm{MN}$, Ayaseh, et al. Factors affecting quality of life in patients on haemodialysis: A cross-sectional study from Palestine. BMC Nephrology 2016; 17(1): 44.

9. Mushi L, Marschall P, Fleßa S. The cost of dialysis in low and middle-income countries: A systematic review. BMC Health Serv Res 2015; 15(1): 506-12.

10. Gérard C, Roger KA, Aïda LM, Gaoussou S, Hien KM, Adama L. Epidemiological profile of chronic hemodialysis patients in Ouagadougou. Open J Nephrol 2016; 6(02): 29-35.

11. Chironda G, Manwere A, Nyamajura R, Chipfuwa T, Behengu B. Perceived health status and adherence to hemodialysis by end stage renal disease patients: A case of a central hospital in Zimbabwe. J Nurs Health Sci 2015; 3(1): 22-31.

12. Yuen SK, Suen HP, Kwok OL, Yong SP, Tse MW. Advance care planning for 600 chinese patients with end-stage renal disease. Hong Kong J Nephrol 2016; 19(1): 19-27.

13. Deif HIA, Elsawi K, Selim M, Nasr-Allah MM. Effect of an educational program on adherence to therapeutic regimen among chronic kidney disease stage 5 (CKD5) patients under maintenance hemodialysis. J Edu Prac 2015; 6(5): 21-33.

14. Mukakarangwa CM, Chironda G, Bhengu B, Katende G. Adherence to hemodialysis and associated factors among end stage renal disease patients at selected nephrology units in rwanda: a descriptive cross-sectional study. Nurs Res Pract 2018; 2018: 1-8.

15. Matsuo T. Disappearance of diabetic macular hard exudates after hemodialysis introduction. Acta Medica Okayama 2006; 60(3): 201-05.

16. Hirasawa $\mathrm{H}$, Tomidokoro A, Araie M, Konno S, Saito H, Iwase A, et al. Peripapillary retinal nerve fiber layer thickness determined by spectral-domain optical coherence tomography in ophthalmologically normal eyes. Arch Ophthalmol 2010; 128(11): 1420-26.

17. Budenz DL, Anderson DR, Varma R, Schuman J, Cantor L, Savell, et al. Determinants of normal retinal nerve fiber layer thickness measured by Stratus OCT. Ophthalmol 2007; 114(6): 1046-52.

18. Hojs R. Carotid intima media thickness and plaques in hemodialysis patients. Artif Organs 2000; 24(9): 691-95. 